\title{
COMPARISON OF THE EFFECTIVENESS OF VISUAL IMAGERY TECHNIQUE AND PROGRESSIVE RELAXATION TECHNIQUE ON ANXIETY AND DEPRESSION IN SUBJECTS WITH MODERATE CHRONIC OBSTRUCTIVE PULMONARY DISEASE
}

\author{
MRUDULA M MHASKE, POOVISHNU DEVI T, VAISHALI KRISHNAT JAGTAP
}

Department of Cardiopulmonary Sciences, Krishna College of Physiotherapy, KIMSDTU, Karad - 415 110, Maharashtra, India.
Email: mrudulamhaske43729@gmail.com

Received: 01 February 2018, Revised and Accepted: 15 March 2018

\section{ABSTRACT}

Objectives: (1) To determine the effectiveness of visual imagery technique (VIT) on anxiety and depression in moderate chronic obstructive lung disease, (2) to determine the effectiveness of progressive relaxation technique (PRT) on anxiety and depression in moderate chronic obstructive lung disease (COPD), and (3) to compare the effectiveness of VIT and PRT on anxiety and depression in moderate COPD.

Methods: Ethical clearance was obtained from the institutional ethical committee. A total of 45 stable moderate COPD patients were selected by simple random sampling, according to inclusion and exclusion criteria. 22 patients of Group A received VIT and 23 of Group B received PRT with a baseline treatment of conventional physiotherapy in both groups for 60 minutes twice a day for 5 days in the Pulmonology Department, Krishna Hospital, Karad.

Result: Statistics was analyzed using paired t-test and unpaired t-test. In pre-intervention, there was no statistically significant difference seen for depression anxiety stress scale (DASS21) ( $\mathrm{p}=\mathrm{D}$ 0.0189, A 0.0002, $\mathrm{S}<0.0001$ ) ( $\mathrm{t}=\mathrm{D} 2.440$, A 4.053, S 5.105), hospital anxiety depression scale (HADS) ( $\mathrm{p}=\mathrm{D}$ 0.7677, A 0.5121) ( $\mathrm{t}=\mathrm{D}$ 0.2973, A 0.6610), and 6-min walk test (6MWT) ( $\mathrm{p}=\mathrm{D}$ 0.5948, RPE 0.0658) ( $\mathrm{t}=\mathrm{D}$ 0.5359, RPE 1.888). On comparing, the post-interventional values between the two groups using unpaired t-test proved that there was extremely statistically significant difference seen for DASS21 ( $\mathrm{p}=\mathrm{D}$ 0.0011, A $<0.0001, \mathrm{~S}<0.0001$ ) ( $\mathrm{t}=\mathrm{D} 3.504, \mathrm{~A} 9.220$, S 13.508), HADS ( $\mathrm{p}=\mathrm{D}<0.0001, \mathrm{~A}<0.0001$ ) ( $\mathrm{t}=\mathrm{D}<0.0001, \mathrm{~A}<0.0001$ ), and 6MWT ( $\mathrm{p}=$ distance $0.7041, \mathrm{RPE}<0.0001)(\mathrm{t}=$ distance $0.3824, \mathrm{RPE}<0.0001)$.

Conclusion: VIT along with conventional physiotherapy was significant both statistically and clinically compared to PRT on anxiety and depression in moderate COPD patients.

Keywords: Visual imagery technique, Progressive relaxation technique, Conventional physiotherapy, Chronic obstructive lung disease, Depression anxiety stress scale, Hospital anxiety depression scale, 6-min walk test, Anxiety, Depression, Stress.

(c) 2018 The Authors. Published by Innovare Academic Sciences Pvt Ltd. This is an open access article under the CC BY license (http://creativecommons. org/licenses/by/4. 0/) DOI: http://dx.doi.org/10.22159/ajpcr.2018.v11i6.25067

\section{INTRODUCTION}

Chronic obstructive pulmonary disease (COPD) is a treatable, preventable, and partially reversible disease characterized by progressive airflow obstruction documented by spirometry; it is associated with an abnormal inflammatory response of the lungs to noxious particles or gases [1].

The prevalence of COPD increases with age, with a 5 -fold increased risk for those aged over 65 years compared with patients aged $<40$ years [2]. The disease is predicted to become the fourth leading cause of death by 2030 accounting for $7.8 \%$ of total deaths [3].

COPD affects twice as many males as females, but this difference will diminish, given the fact that more and more females throughout the world have taken up smoking in the past few years in developed countries and that non-smoking females are exposed to biomass combustion products in developing countries. Recent studies suggest that overall prevalence and incidence of COPD are higher in men [4-6]; the incidence of COPD in younger age groups is now much higher in women [4]. Women may be more susceptible to developing COPD, are more likely to express the airway-predominant subtype, and report more severe symptoms and activity intolerance.

The common symptoms of COPD are cough, sputum, impaired exercise tolerance, and wheezing which are considered as the primary manifestation of COPD. The secondary manifestation includes ischemic heart disease, osteoporosis, posture, balance, anxiety, depression, skeletal muscle dysfunction, anemia, diabetes, metabolic syndrome, gastroesophageal reflux, and lung cancer.

The most common complications of COPD have constrained activity, weight loss, increased cardiovascular risk, osteoporosis, pneumonia, cor pulmonale, pneumothorax, pulmonary hypertension, and in some cases develop depression [7].

Patients with COPD frequently find themselves in a vicious cycle of dyspnea, deteriorating exercise performance, restricted mobility, and social isolation. Anxiety and/or depression are also important parts of that cycle [8]. This cycle of anxiety and depression repeats itself over and over again in a vicious cycle as shown in Fig. 2.

Physiotherapist focuses more on primary manifestations only, as a part of their treatment protocol, but the secondary manifestations which lead to morbidity and mortality remain unnoticed and untreated with focus on the point that they can be managed with medications effectively which is not true.

Anxiety and depression occur together mainly due to breathlessness, but management is not focused in terms that it resolves spontaneously after the exacerbation. Recent studies have proved that specific relaxation techniques reduce anxiety and depression in COPD patients. However, no study has been done in comparing visual imagery technique (VIT) and progressive relaxation technique (PRT) for reduction of anxiety and depression in COPD subjects till date. Hence, the need of the study is to 
compare the effectiveness of VIT and PMR on anxiety and depression in moderate COPD subjects.

\section{VIT}

The use of imagery technique is effective in reducing the levels of anxiety, depression, and body discomfort in patients. Visual imagery meditation is a gentle, but powerful technique that focuses and directs the imagination in proactive, positive ways. It can be just as simple as an athlete's 10-second reverie, just before leaping off the diving board, imagining how a perfect dive feels when slicing through the water. VITs involve all of the senses, and almost anyone can do this.

\section{PRT}

PRT is a technique of systematically tensing and releasing of muscles developed by Dr. Edmund Jacobson in the 1930s and described in his book progressive relaxation. This technique is a muscle relaxation technique and can relax body within minutes. Progressive relaxation is based on the fact that complete physical relaxation is the absence of muscle tension.

\section{METHODS}

It was a comparative study conducted in the Physiotherapy Department of Krishna Institute of Medical Sciences. 45 patients were divided into two groups using simple random sampling. Conventional physiotherapy was given as a baseline treatment to both groups.

\section{Sampling method}

Group A was given VIT, and Group B was given PRT. The patients were selected according to inclusion and exclusion criteria. Written informed consent was taken and the whole study was explained to them. Inclusion criteria were as follows: (1) Both male and female, (2) diagnosed with COPD with PFT values of forced expiratory volume in one second (FEV1)/forced vital capacity $\%<70 \%$ and FEV1 is $<80 \%$, (3) hospital anxiety depression scale (HADS) score of 8-12, and (4) ability to provide informed consent. Exclusion criteria were as follows: (1) Inability to communicate because of language skills, (2) hearing and cognitive impairment, (3) subjects who received tricyclic antidepressants or other antipsychotic drugs for past 3 months, (4) symptomatic cardiovascular disease, uncontrolled hypertension, and (5) evidence of neurological or musculoskeletal condition which affect sitting or supine lying posture for long time.
Group A - VIT (30 min) with conventional physiotherapy treatment (i.e., breathing exercise, incentive spirometry, and dyspnea relieving positions) (30 min) (1 set) (2 times per day).

Group B - PRT (30 min) with conventional physiotherapy treatment (i.e., breathing exercise, incentive spirometry, and dyspnea relieving positions) (30 min) (1 set) (2 times per day).

\section{RESULTS}

A total of 45 subjects based on the inclusion and exclusion criteria were divided into two groups in which Group A $(n=22)$ received VIT while Group B $(n=23)$ received PRT with conventional therapy as baseline treatment for both groups using simple random sampling technique.

DASS21 - Intragroup comparison (within the group) using the paired t-test.

In Group A, the mean DASS21 score on pre-intervention was $16.54 \pm 3.21$ for depression, $11.18 \pm 4.47$ for anxiety, and $12.45 \pm 2.68$ for stress which was reduced to a mean of $6.27 \pm 2.25$ for depression, $3.63 \pm 1.46$ for anxiety, and $4 \pm 1.38$ for stress postsessions. p-value by paired t-test was found to be $<0.0001$, which is extremely statistically significant.

In Group B, the mean VAS score on pre-intervention was $5.21 \pm 1.295$, which was reduced to a mean of $4.88 \pm 1.35$ post-intervention. p-value by paired t-test was found to be 0.0043 , which is very statistically significant (Table 1).

HADS - Intragroup comparison (within the group) using the paired t-test.

In Group A, the mean HADS score on pre-intervention was $10.04 \pm 1.36$ for depression, $9.59 \pm 1.43$ for anxiety, which was reduced to a mean of $3.45 \pm 1.05$ for depression, and 3.09 \pm 1.065 for anxiety in postsession. p-value by paired t-test was found to be $<0.0001$, which is extremely statistically significant.

In Group B, the mean HADS score on pre-intervention was $13.615 \pm 1.557$ for depression, $13.153 \pm 1.819$ for anxiety, which was reduced to a mean of $5.30 \pm 1.185$ for depression, and $5.08 \pm 1.505$ for anxiety postintervention. p-value by paired t-test was found to be $<0.0001$, which is extremely statistically significant (Table 2).

Table 1: Comparison of pre- and post-DASS21 values within the groups

\begin{tabular}{|c|c|c|c|c|c|c|}
\hline \multirow[t]{2}{*}{ Group } & \multicolumn{2}{|c|}{ Pre-treatment } & \multicolumn{2}{|c|}{ Post-treatment } & \multirow[t]{2}{*}{$\mathbf{t}$} & \multirow[t]{2}{*}{$\mathbf{p}$} \\
\hline & Mean \pm SD & Median & Mean $\pm S D$ & Median & & \\
\hline \multicolumn{7}{|l|}{$\mathrm{A}$} \\
\hline $\mathrm{D}$ & $16.54 \pm 3.21$ & 16 & $6.27 \pm 2.25$ & 6 & 23.28 & $<0.0001^{* * *}$ \\
\hline A & $11.18 \pm 4.47$ & 10 & $3.63 \pm 1.46$ & 4 & 9.702 & $<0.0001^{* * *}$ \\
\hline $\mathrm{S}$ & $12.45 \pm 2.68$ & 12 & $4 \pm 1.38$ & 4 & 16.627 & $<0.0001^{* * *}$ \\
\hline \multicolumn{7}{|c|}{ 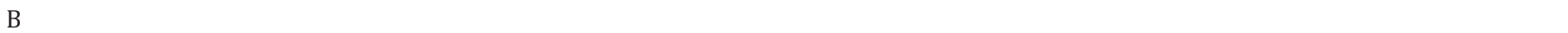 } \\
\hline D & $14.17 \pm 3.29$ & 14 & $8.69 \pm 2.38$ & 8 & 10.819 & $<0.0001^{* * *}$ \\
\hline A & $16.78 \pm 4.77$ & 18 & $9.13 \pm 2.39$ & 10 & 10.338 & $<0.0001^{* * *}$ \\
\hline $\mathrm{S}$ & $17.3 \pm 3.59$ & 18 & $11.56 \pm 2.25$ & 12 & 8.158 & $<0.0001^{* * *}$ \\
\hline
\end{tabular}

Table 2: Comparison of pre- and post-HADS values within the groups

\begin{tabular}{|c|c|c|c|c|c|c|}
\hline \multirow[t]{2}{*}{ Group } & \multicolumn{2}{|c|}{ Pre-treatment } & \multicolumn{2}{|c|}{ Post-treatment } & \multirow[t]{2}{*}{$\mathbf{t}$} & \multirow[t]{2}{*}{$\mathbf{p}$} \\
\hline & Mean \pm SD & Median & Mean \pm SD & Median & & \\
\hline \multicolumn{7}{|l|}{ A } \\
\hline $\mathrm{D}$ & $10.04 \pm 1.36$ & 10 & $3.45 \pm 1.05$ & 4 & 20.173 & $<0.0001^{* * *}$ \\
\hline A & $9.59 \pm 1.43$ & 9.5 & $3.09 \pm 1.065$ & 3 & 15.476 & $<0.0001^{* * *}$ \\
\hline \multicolumn{7}{|c|}{ 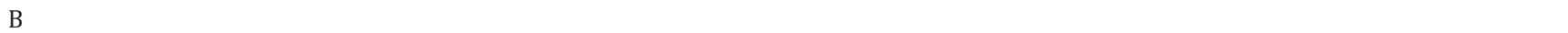 } \\
\hline $\mathrm{D}$ & $10.17 \pm 1.527$ & 10 & $5.30 \pm 1.185$ & 5 & 14.823 & $<0.0001^{* * *}$ \\
\hline
\end{tabular}


6MWT - Intragroup comparison (within the group) using the paired t-test.

In Group A, the mean 6MWT score on pre-intervention was $231.9 \pm 62.5$ for distance, $14 \pm 0.81$ for RPE, which was reduced to a mean of $294.9 \pm 62.2$ for distance, and $8.45 \pm 0.59$ for RPE in postsession. p-value by paired t-test was found to be $<0.0001$, which is extremely statistically significant.

In Group B, the mean 6MWT score on pre-intervention was $242.08 \pm 64.75$ for distance, $14.43 \pm 0.72$ for RPE, which was reduced to a mean of $302.08 \pm 63.65$ for distance, and $11.13 \pm 0.62$ for RPE postintervention. p-value by paired t-test was found to be $<0.0001$, which is extremely statistically significant (Table 3 ).

DASS21 - Intergroup (between the groups) comparison using the unpaired t-test.

On comparing the pre-interventional values, the results between the two groups using unpaired t-test revealed that there was statistically significant difference seen with $\mathrm{p}=$ depression -0.0189 , anxiety -0.0002 , and stress $-<0.0001$, while on comparing the postsession values, the results between the two groups using unpaired t-test revealed that there was very significant difference seen with $p=$ depression -0.0011 and anxiety and stress - $<0.0001$ (Table 4).

The values were compared by applying unpaired t-test. Pre-treatment shows that there is a statistically significant difference in the DASS21 scores ( $\mathrm{p}=$ depression -0.0189 , anxiety -0.0002 , and stress $-<0.0001$ ), whereas post-treatment shows extremely statistically significant difference $(\mathrm{p}=$ depression -0.0011 and anxiety and stress $-<0.0001)$ (Table 4).

HADS - Intergroup (between the groups) comparison using the unpaired t-test.

On comparing the pre-interventional values, the results between the two groups using unpaired t-test revealed that there was no statistically significant difference seen with $\mathrm{p}=$ depression - 0.7677 and anxiety - 0.5121. While on comparing the postsession values, the results between the two groups using unpaired t-test revealed that there was extremely statistically significant difference seen with $\mathrm{p} \leq 0.0001$ (Table 5).

The values were compared by applying unpaired t-test. Pre-treatment shows that there is no statistically significant difference in the HADS scores ( $\mathrm{p}=$ depression -0.7677 and anxiety - 0.5121), whereas posttreatment shows an extremely statistically significant difference $(\mathrm{p} \leq 0.0001)$ (Table 5).

6MWT - Intergroup (between the groups) comparison using the unpaired t-test.

On comparing the pre-interventional values, the results between the two groups using unpaired t-test revealed that there was no statistically significant difference seen with $\mathrm{p}=$ distance -0.5948 and RPE -0.0658 . While on comparing the postsession values, the results between the two groups using unpaired t-test revealed that there was no significant difference between distance covered in 6MWT with $\mathrm{p}=0.7041$ but extremely statistically significant difference seen with the RPE score $\mathrm{p} \leq 0.0001$ (Table 6).

The values were compared by applying unpaired t-test. Pre-treatment shows that there is no statistically significant difference in the 6MWT scores ( $\mathrm{p}=$ distance 0.5948 and RPE 0.0658 ), whereas post-treatment showed no statistically significant difference between distance covered in 6MWT $(\mathrm{p}=0.7041)$ but extremely statistically significant difference seen with the RPE score $(p \leq 0.0001)$ (Table 6).
Table 3: Comparison of pre- and post-6MWT values within the groups

\begin{tabular}{|c|c|c|c|c|}
\hline \multirow[t]{2}{*}{ Group } & \multicolumn{2}{|l|}{ Mean \pm SD } & \multirow[t]{2}{*}{$\mathbf{t}$} & \multirow[t]{2}{*}{$\mathbf{p}$} \\
\hline & Pre-treatment & Post-treatment & & \\
\hline \multicolumn{5}{|l|}{$A$} \\
\hline Distance & $231.9 \pm 62.5$ & $294 \pm 62.2$ & 7.094 & $<0.0001^{* * *}$ \\
\hline RPE & $14 \pm 0.81$ & $8.45 \pm 0.59$ & 24.61 & $<0.0001^{* * *}$ \\
\hline \multicolumn{5}{|l|}{$\mathrm{B}$} \\
\hline Distance & $242.08 \pm 64.75$ & $302.08 \pm 63.65$ & 6.339 & $<0.0001^{* * *}$ \\
\hline RPE & $14.43 \pm 0.72$ & $11.13 \pm 0.62$ & 17.111 & $<0.0001^{* * *}$ \\
\hline
\end{tabular}

Table 4: Comparison of pre- and post-DASS21 values of between the groups

\begin{tabular}{lll}
\hline Group & Mean \pm SD & \\
\cline { 2 - 3 } & Pre-treatment & Post-treatment \\
\hline A & $16.54 \pm 3.218$ & $6.27 \pm 2.25$ \\
D & $11.18 \pm 4.47$ & $3.63 \pm 1.46$ \\
A & $12.45 \pm 2.68$ & $4 \pm 1.380$ \\
S & & \\
B & $14.17 \pm 3.298$ & $8.69 \pm 2.38$ \\
D & $16.82 \pm 4.77$ & $9.13 \pm 2.39$ \\
A & $17.30 \pm 3.59$ & $11.56 \pm 2.25$ \\
S & & \\
t & 2.440 & 3.504 \\
D & 4.053 & 9.220 \\
A & 5.105 & 13.508 \\
S & & \\
p-value & $0.0189^{*}$ & $0.0011^{* *}$ \\
D & $0.0002^{* * *}$ & $<0.0001^{* * *}$ \\
A & $<0.0001^{* * *}$ & $<0.0001^{* * *}$ \\
S & significant, $* *$ very significant, ${ }^{* * *}$ extremely significant. SD: Standard deviation
\end{tabular}

Table 5: Comparison of pre- and post-HADS values of between the groups

\begin{tabular}{lll}
\hline Group & Mean \pm SD & \\
\cline { 2 - 3 } & Pre-treatment & Post-treatment \\
\hline A & $10.04 \pm 1.36$ & $3.45 \pm 1.057$ \\
D & $9.59 \pm 1.4$ & $3.09 \pm 1.065$ \\
A & & \\
B & $5.54 \pm 0.1 .76$ & $5.30 \pm 1.18$ \\
D & $4 \pm 1.74$ & $5.08 \pm 1.50$ \\
A & & \\
t & 0.2973 & 5.519 \\
D & 0.6610 & 5.115 \\
A & & \\
p-value & 0.7677 & $<0.0001 * * *$ \\
D & 0.5121 & $<0.0001^{* * *}$ \\
A & *** &
\end{tabular}

\section{DISCUSSION}

Anxiety and depression are considered a problematic issue because it restricts the person from day to day life activities. It limits the individual from doing any activities since it increases breathlessness in the individual. The purpose of this study was to compare the effectiveness of the VIT and PRT on anxiety and depression in subjects with moderate COPD.

Of 45 subjects, 31 were males and 14 were females. The mean age of the subjects included in Group A was 42.3 and Group B was 43.8. 
Table 6: Comparison of pre- and post-6MWT values between the groups

\begin{tabular}{lll}
\hline Group & Mean \pm SD & \\
\cline { 2 - 3 } & Pre-treatment & Post-treatment \\
\hline A & $231.9 \pm 4.180$ & $302 \pm 62.2$ \\
Distance & $14 \pm 5.606$ & $8.45 \pm 0.59$ \\
RPE & & \\
B & $242.08 \pm 6.061$ & $294 \pm 63.65$ \\
Distance & $14.43 \pm 0.72$ & $11.13 \pm 0.62$ \\
RPE & & \\
t & 0.5359 & 0.3824 \\
Distance & 1.888 & 14.681 \\
RPE & & \\
p-value & 0.5948 & 0.7041 \\
Distance & $0.0658^{*}$ & $<0.0001^{* * *}$ \\
RPE & r &
\end{tabular}

${ }^{*}$ significant, ${ }^{* * *}$ extremely significant. 6MWT: 6-min walk test

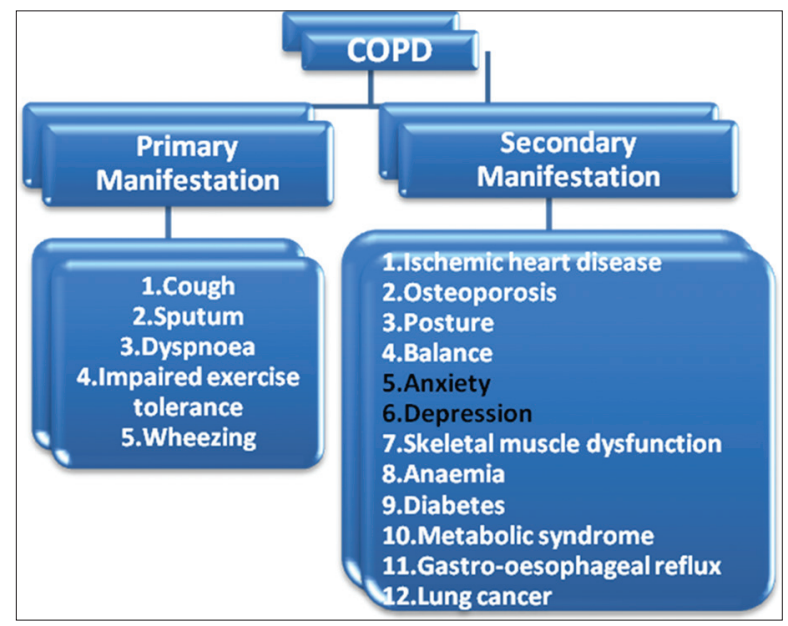

Fig. 1: Primary and Secondary Manifestation of chronic obstructive lung disease

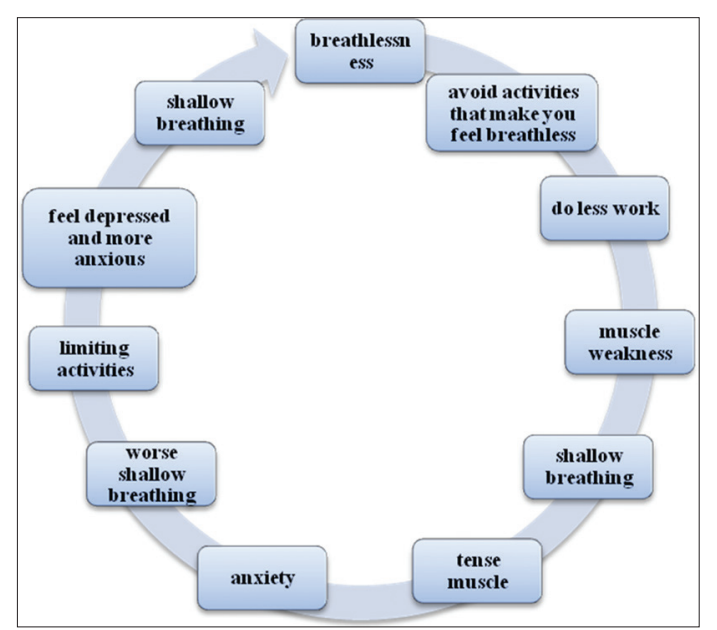

Fig. 2: Vicious Cycle of Anxiety and Depression in COPD

Intragroup comparison (within the group) was analyzed statistically using the paired t-test for DASS21, HADS, and 6MWT scores, and intergroup comparison (between the groups) was analyzed statistically using the unpaired t-test.

Recent studies proved specific relaxation techniques reduce anxiety and depression in COPD patients. However, no study has been done

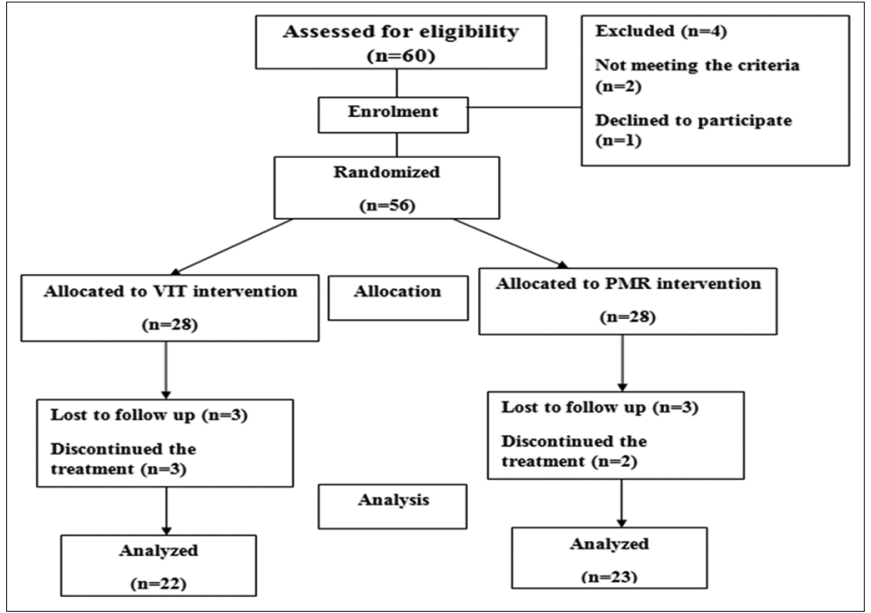

Fig. 3: Flow diagram of allocation of patients, intervention, dropouts, and analysis $(n=45)$

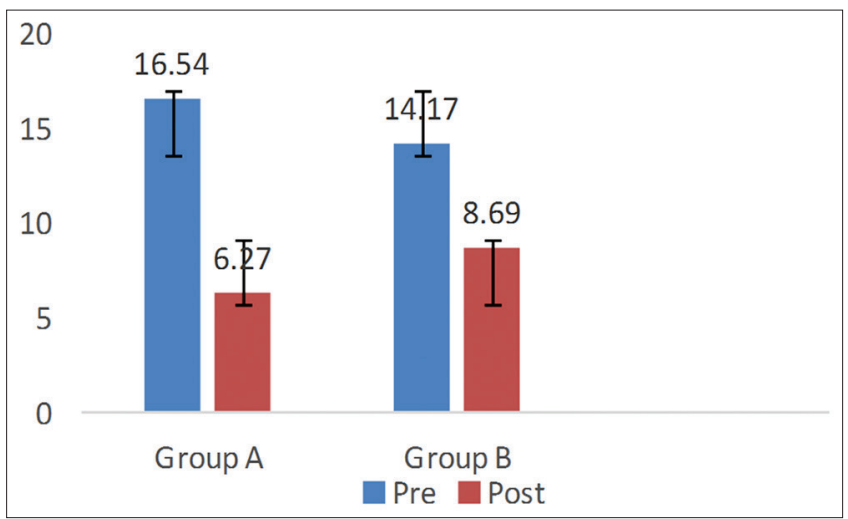

Fig. 4: Comparison of pre and post Mean \pm SD values within the group of DASS21- Depression score

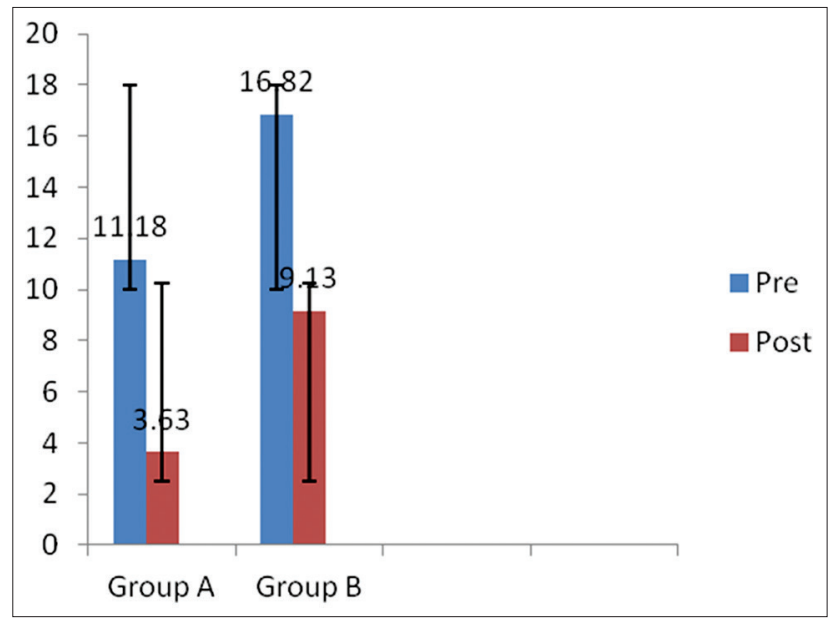

Fig. 5: Comparison of pre and post Mean \pm SD values within the group of DASS21- Anxiety score

in comparing VIT and PRT for reduction of anxiety and depression in COPD subjects till date.

In this study, an attempt was made to compare the effect of both techniques, i.e. VIT and PRT on reduction of anxiety and depression in moderate COPD subjects. The results showed extremely significant reduction of anxiety and depression for VIT in moderate COPD subjects as compared to PRT. 


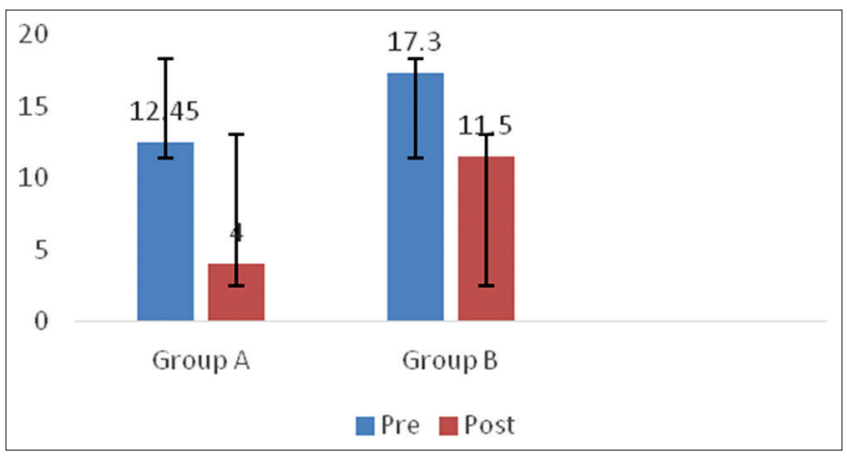

Fig. 6: Comparison of pre and post Mean \pm SD values within the group of DASS21- Stress scores

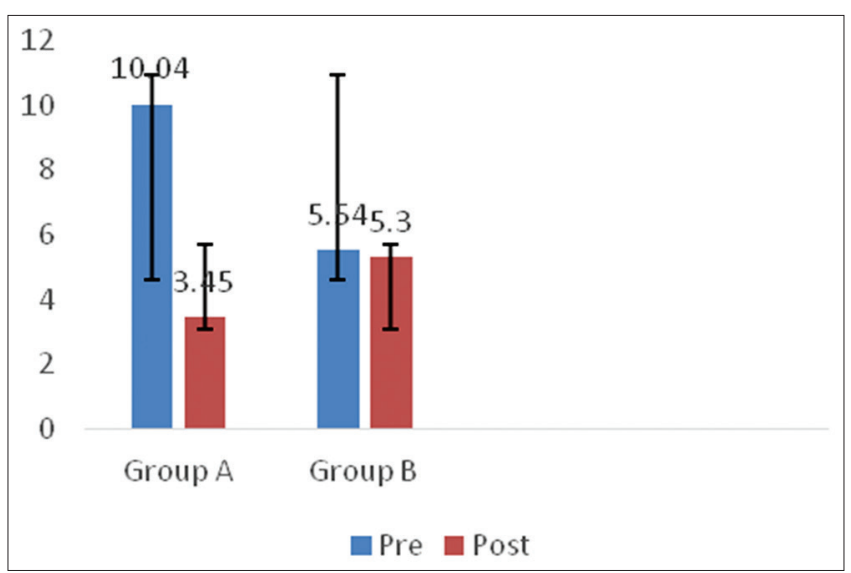

Fig. 7: Comparison of pre and post Mean \pm SD values within the group HADS score- Depression Score

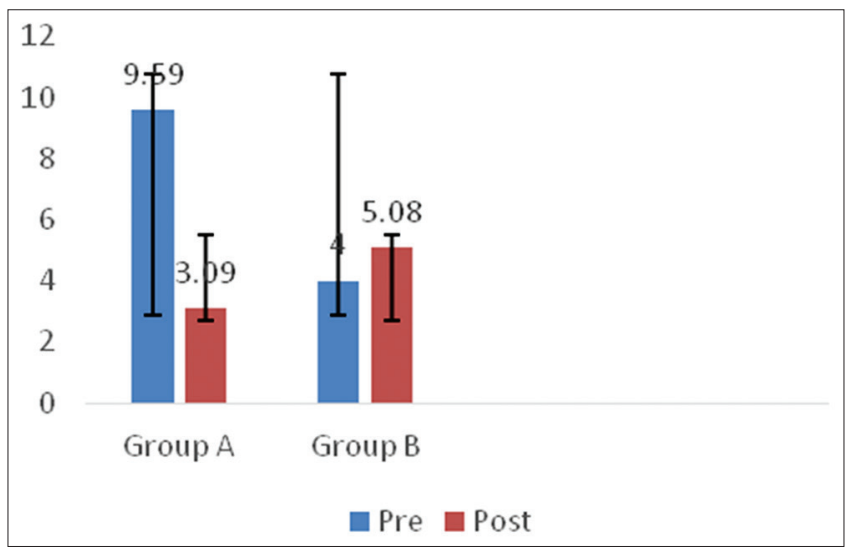

Fig. 8: Comparison of pre and post Mean \pm SD values within the group HADS score- Anxiety Score

The use of imaging technique is effective in reducing the levels of anxiety, depression, and body discomfort in patients. Visual imagery meditation is a gentle, but powerful technique that focuses and directs the imagination in proactive, positive ways. Mental imagery, especially visual and auditory imagery, can exacerbate and aggravate a number of mental and physical conditions [9]. It is because, according to the principles of psychophysiology and psychoneuroimmunology, the way an individual perceives his or her mental and physical condition, in turn, affects biological processes including susceptibility to illness, infection, or disease and that perception is derived significantly from mental imagery. That is to say that in some cases, the severity of an individual's mental and physical disability, disorder, or illness is

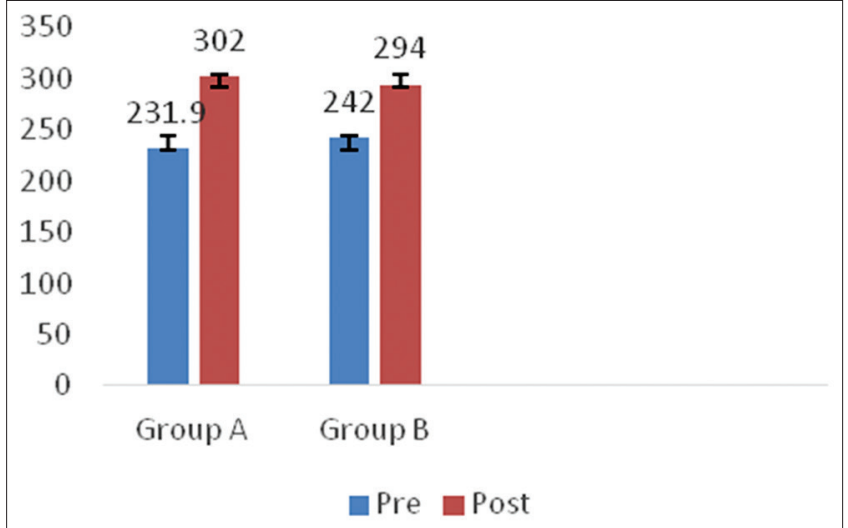

Fig. 9: Comparison of pre and post Mean \pm SD values within the group 6MWT-distance score

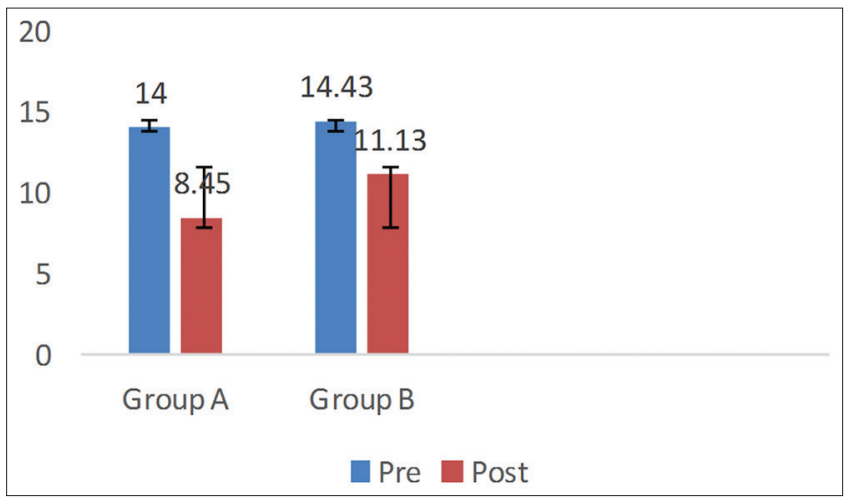

Fig. 10: Comparison of pre and post Mean \pm SD values within the group of 6MWT- RPE score

partially determined by his or her images including their content, vividness or intensity, clarity, and the frequency with which they are experienced as intrusive and unbidden [10-12].

\section{CONCLUSION}

VIT along with conventional physiotherapy was significant both statistically and clinically compared to PRT on anxiety and depression in moderate COPD patients.

\section{ACKNOWLEDGMENT}

We acknowledge the guidance and constant support of Dr. Varadharajulu G, Dean, Faculty of Physiotherapy, Karad, Dr. T. Poovishnu Devi, Dr. Vaishali Jagtap, and Dr. Kakade SV, for help in statistical analysis.

\section{AUTHOR'S CONTRIBUTION}

Mrudula M Mhaske: Conducted literature review for this manuscript, developed introduction section of the manuscript together with the discussion of the study findings, collected data and analyzed the data.

T. Poovishnu Devi: Provided a description of the background information and participated in preparation of the manuscript.

Vaishali Krishnat Jagtap: Participated in approval of the manuscript.

All the authors read and approved the final manuscript.

\section{CONFLICT OF INTEREST}

The authors declare that there is no conflict of interest concerning the content of the present study. 


\section{REFERENCES}

1. Littner MR. Chronic obstructive pulmonary disease. Ann Intern Med 2011;154:ITC4-1.

2. Postma DS, Siafakas N, editors. Epidemiology of chronic obstructive lung disease in management of chronic obstructive lung disease. Eur Respir Mon 1998;7:41-73.

3. Unni A, Jayaprakash AK, Mc Y, Devi PU. Drug utilization pattern in chronic Obstructive pulmonary disease inpatients at a tertiary care hospital. Int J Pharm Pharm Sci 2015;7:389-91.

4. van Durme YM, Verhamme KM, Stijnen T, van Rooij FJA, Van Pottelberge GR, Hofman A, et al. Prevalence, incidence, and lifetime risk for the development of COPD in the elderly: The rotterdam study. Chest 2009;135:368-77.

5. Buist AS, McBurnie MA, Vollmer WM, Gillespie S, Burney P, Mannino DM, et al. International variation in the prevalence of COPD (the BOLD study): A population-based prevalence study. Lancet 2007;370:741-50.

6. Menezes AM, Perez-Padilla R, Jardim JR, Muiño A, Lopez MV,
Valdivia G, et al. Chronic obstructive pulmonary disease in five Latin American cities (the PLATINO study): A prevalence study. Lancet 2005;366:1875-81.

7. Mahmudah RL, Ikawati Z, Wahyono D. A qualitative study of perspectives, expectations and needs of education in chronic obstructive pulmonary disease (COPD). Int J Curr Pharm Res 2017;9:32-5.

8. Regvat J, Zmitek A, Vegnuti M, Kosnik M, Suskovic S. Anxiety and depression during hospital treatment of exacerbation of chronic obstructive pulmonary disease. J Intern Med Res 2011;39:1028-38.

9. Ader R. A Historical account of conditioned immunobiologic responses. Psvchoneuroimmunology. New York: Academic Press; 1981. p. 321-52.

10. Borysenko J. Psychoneuroimmunology: Behavioural factors and the immune response. Revision 1984;7:56-65.

11. Rossi E. The Psychobiology of Mind-Body Healing. New York: W.W. Norton and Company, Inc.; 1986.

12. Ehlers A, Clark DM. A cognitive model of posttraumatic stress disorder. Behav Res Ther 2000;38:319-45.

Author Queries???

AQ1: Kindly cite figure 1 and 3-10 in the text part 